\title{
Dorstenia (Moraceae) da região da Serra da Mantiqueira, Brasil
}

\author{
Dorstenia (Moraceae) from Mantiqueira ridge, Brazil
}

\author{
Alessandra dos Santos ${ }^{1,2,4}$, Patricia Aparecida de São José ${ }^{2}$, Marcelo Dias Machado Vianna Filho ${ }^{3}$ \& \\ Sergio Romaniuc Neto ${ }^{2}$
}

\begin{abstract}
Resumo
A Serra da Mantiqueira é uma formação montanhosa que ocupa importante área do Sudeste brasileiro. Entre as famílias ricas em espécies na composição da flora da Mantiqueira está Moraceae, sendo que Dorstenia se destaca como o segundo gênero mais representativo em número de espécies, depois de Ficus. Neste trabalho são apresentadas descrições, observações sobre fenologia e distribuição geográfica, comentários e ilustrações das espécies nativas de Dorstenia (Moraceae). Após o levantamento bibliográfico e análise do material coletado e de herbário foi possível reconhecer 14 espécies nativas, sendo, duas novas espécies que foram descritas durante a realização deste estudo.
\end{abstract}

Palavras-chave: Conservação, Diversidade, Dorstenieae, Mata Atlântica, Florística.

\begin{abstract}
Mantiqueira Ridge is a chain of mountains that represents an important area of Brazilian southeastern. Moraceae is among the richest families on species's diversity of Mantiqueira's flora, being that Dorstenia stands out as the second genus more representative in number of species, after of Ficus. This paper presents descriptions, observations on phenology and geographic distribution, comments and illustrations of native species of Dorstenia (Moraceae). After reviewing the bibliography and analyzing the collected material and botanical collections, 14 native species were found within Mantiqueira Ridge, among them, two new species described during this study.
\end{abstract}

Key words: Conservation, Diversity, Dorstenieae, Atlantic Rainforest, Floristic.

\section{Introdução}

A Serra da Mantiqueira é uma formação montanhosa que ocupa importante área do Sudeste brasileiro, entre a costa atlântica e as terras interiores do país. A região foi considerada, em um estudo feito pela IUCN, como a $8^{\mathrm{a}}$ área protegida mais insubstituível da Terra (Saout et al. 2014). Entre as famílias ricas em espécies na composição da flora da Mantiqueira está Moraceae, sendo que, Dorstenia L. é o segundo gênero mais representativo em número de espécies. A família compreende 38 gêneros e cerca de 1.150 espécies, está representada principalmente na região tropical, com mais de $50 \%$ dos gêneros na região Neotropical desde o México até a Argentina. No Brasil ocorrem 19 gêneros e aproximadamente 200 espécies, destas 70 endêmicas (BFG 2015).
Suas espécies são reconhecidas por apresentarem estípulas terminais, livres ou unidas, presença de laticíferos distribuídos por todas as partes da planta, folhas simples e alternas. Suas espécies podem ser monoicas ou dioicas com inflorescências axilares, bissexuadas ou unissexuadas, racemosas ou cimosas e flores aclamídeas ou monoclamídeas.

O gênero Dorstenia apresenta o hábito herbáceo sendo encontrado nas áreas tropicais da América, Ásia e África e compreende cerca de 105 espécies (Berg \& Hijiman 1999). No Brasil ocorrem 38 espécies nativas (Romaniuc Neto et al. 2015; Santos \& Romaniuc Neto 2012; Vianna Filho 2012), destas 33 são endêmicas. Caracteriza-se principalmente pelo hábito herbáceo, presença de rizomas e inflorescência do tipo cenanto.

\footnotetext{
${ }^{1}$ Parte da dissertação de Mestrado apresentada pela primeira autora ao Programa de Pós-graduação em Biodiversidade Vegetal e Meio Ambiente do Instituto de Botânica.

${ }^{2}$ Instituto de Botânica, Núcleo de Pesquisa Curadoria do Herbário SP, Av. Miguel Estéfano 3687, 04301-902, Água Funda, São Paulo, SP, Brasil.

${ }^{3}$ Instituto de Pesquisas Jardim Botânico do Rio de Janeiro, R. Pacheco Leão 915, s1. 208, 22460-030, Rio de Janeiro, RJ, Brasil.

${ }^{4}$ Autor para correspondência: ale.san.bot@gmail.com
} 
Diante da diversidade e elevado número de endemismos apresentado pelas espécies de Dorstenia e pelas peculiaridades da área da Serra da Mantiqueira, esse trabalho objetivou descrever as espécies, apresentar comentários morfológicos e taxonômicos e a distribuição geográfica das espécies de Dorstenia da Serra da Mantiqueira.

\section{Material e Métodos}

A região onde se encontra a Serra da Mantiqueira está localizada no Sudeste do Brasil, ocupando partes dos estados de São Paulo, Rio de Janeiro, Minas Gerais e Espírito Santo (Mendes Júnior et al. 1991; Hueck 1972; Rizzini 1979). Para este trabalho, a área de estudo foi delimitada de acordo com os trabalhos de Pelissari \& Romaniuc Neto (2013), CETEC (1983), Várzea (1942), Santos (2012), Lima (2008), Colabardini (2003) e Garcia Júnior (2011). Expedições ao campo foram realizadas com o objetivo de complementar as coleções de Dorstenia da Serra da Mantiqueira e observar as espécies em seu ambiente natural. Todo o material coletado foi processado de acordo com os métodos usuais em taxonomia (Fidalgo \& Bononi 1989), processados segundo Mori et al. (1989) e depositado no herbário do Instituto de Botânica de São Paulo (SP). Os materiais dos herbários visitados (BHCB, CESJ, GFJP, GUA, HB, HRCB, IAC, PMSP, R, RB, SP, SPF, SPSF, UEC, VIC) (Thiers 2014) serviram de base para análise do material de Dorstenia da Serra da Mantiqueira. Adotou-se Laurence (1968), Hickey (1973), Font-Quer (1985), Radford et al. (1974), Weberling (1989), Bell (1993) e Stearn (2004) como referências para a terminologia morfológica e ainda Raunkiaer (1934) para as formas de vida. Como complementação, utilizou-se Carauta (1978) e Berg (2001) para as estruturas reprodutivas. O tratamento e descrições taxonômicas das espécies seguiram Mcneill \& Turland 2011, Mcneill et al.
2012 e Prado et al. (2011). Todo material selecionado encontra-se fértil.

\section{Tratamento Taxonômico}

Dorstenia L., Sp. Pl. 1: 121. 1753.

Ervas ou subarbustos (caméfitos, hemicriptófitos, criptófitos e nanofanerófitos); rizomatosas; monoicas. Estípulas não amplexicaules, membranáceas a coriáceas, subuladas ou foliáceas, persistentes a caducas. Folhas inteiras e/ou lobadopinadas, espiraladas a dísticas ou rosuladas; lâminas de forma variável, membranáceas a cartáceas; nervação broquidódroma, actinódroma ou menos frequentemente craspedódroma. Inflorescências (cenanto) uni ou bissexuais, pateliformes, infundibuliformes, filiformes ou espiralados, inteiros ou bifurcados, arredondados, elípticos, obovados a lineares ou angulados a estrelados, margem membranácea ou carnosa, urceolada ou não, provida ou não de apêndices filiformes e/ou brácteas sésseis, ovadas a oblongo-deltoides. Flores imersas no cenanto. Flores estaminadas: perianto tépalas $2(-3)$; estames $2(-3)$ curvos no botão, retos e exsertos posteriormente. Flores pistiladas: perianto segmentado; ovário e estilete imersos no receptáculo carnoso. Drupas exocarpo carnoso. Sementes sem endosperma, hilo triangular, embrião transverso e uncinado, cotilédones delgados, em forma de leque.

A maioria das espécies de Dorstenia da Serra da Mantiqueira é ciófila, entretanto algumas espécies conseguem viver em ambientes ensolarados, como Dorstenia brasiliensis Lam. Na Serra da Mantiqueira Dorstenia está representada por 14 espécies nativas, caracterizadas principalmente como ervas ou subarbustos, com inflorescências (cenanto) e receptáculos providos de brácteas sésseis e podem ser reconhecidas pela chave de identificação abaixo:

\section{Chave para identificação das espécies de Dorstenia da Serra da Mantiqueira}

1. Cenantos bifurcados

7. Dorstenia dolichocaula

1'. Cenantos inteiros.

2. Estípulas subuladas, estreito triangulares, até $4 \mathrm{~mm}$ compr.

3. Caules parcialmente lignificados na porção basal; cenantos arredondados; flores estaminadas a maioria concentrada na periferia do cenanto 12. Dorstenia turnerifolia

3'. Caules inteiramente fibrosos; cenantos angulados a estrelados; flores estaminadas distribuídas por todo o cenanto.

4. Base das lâminas agudo-atenuada; cenantos angulados

4. Dorstenia bowmaniana

4'. Base das lâminas cordadas; cenantos estrelados 14. Dorstenia stellaris 
2'. Estípulas foliáceas, ovado a oblongo-deltoides, $\geq 4 \mathrm{~mm}$ compr.

5. Folhas pseudodígito-trifoliadas; cenantos infundibufilormes

3. Dorstenia bonijesu

5'. Folhas inteiras e/ou lobadas; cenantos pateliformes, filiformes ou espiralados.

6. Caméfitos, hemicriptófitos ou criptófitos; entrenós até $5 \mathrm{~mm}$ compr.

7. Caméfitos; lâminas inteiras e/ou frequentemente lobado-pinadas, maiores que $12 \mathrm{~cm}$ compr; pecíolos maiores que $\geq 17 \mathrm{~cm}$ compr

2. Dorstenia arifolia

7'. Criptófitos a hemicriptófitos a; folhas inteiras ou lobadas, menores que $\leq 10 \mathrm{~cm}$ compr.; pecíolos menores que $17 \mathrm{~cm}$ compr.

8. Folhas lobadas quando adultas; cenantos urceolados

13. Dorstenia vitifolia

8'. Folhas inteiras; cenantos planos.

9. Lâminas cartáceas a coriáceas; margem inteira a levemente crenada; pecíolos $1-4 \mathrm{~cm}$ compr..

5. Dorstenia brasiliensis

9'. Lâminas membranáceas; margem inteira a remotamente ondulada; pecíolos 6-15 cm compr.

6. Dorstenia cayapia

6'. Caméfitos a nanofanerófitos; entrenós maiores que $\geq 1 \mathrm{~cm}$ compr.

10. Margem dos cenantos provida de apêndices filiformes.

11. Apêndices irregulares curvos, delgados 10. Dorstenia strangii

11'. Apêndices regulares, retos, espessos . 1. Dorstenia acangatara

10'. Margem dos cenantos sem apêndices.

12. Cenantos arredondados, elípticos a oblongo-arredondados ou algumas vezes côncavos; pedúnculos com inserção cêntrica no receptáculo

8. Dorstenia elata

12'. Cenantos lineares; pedúnculos com inserção excêntrica no receptáculo.

13. Cenantos filiformes

11. Dorstenia. sucrei

13'. Cenantos espiralados

9. Dorstenia mariae

1. Dorstenia acangatara M.D.M. Vianna, Al. Santos, A.F.P. Machado, Mansano \& Romaniuc, Phytotaxa 118(2): 30-33. $2013 . \quad$ Fig. 1a-b

Caméfitos 30-50 cm alt.; caule aéreo ereto ou decumbente, glabro a pubérulo; entrenós 1-3 $\mathrm{cm}$ compr. Estípulas 5-6 mm compr., foliáceas, ovadas a oblongas, persistentes, glabras a hirsutas. Folhas inteiras, espiraladas; lâminas 14-19 × 10-12 cm, cordada a sagitada, membranáceas, ápice agudo a obtuso-acuminado, base cordada, margem inteira a denticulada, face adaxial glabra a hirsuta, tricomas esparsos, alvos, face abaxial pubérula a hirsuta; nervação broquidódroma, 6-7 pares de nervuras secundárias, nervuras terciárias reticuladas a escaliformes; pecíolos 10-12 cm compr., pubérulos. Cenantos inteiros, 1-1,2 cm diâm., pateliformes, verde escuros externamente, vermelho-arroxeados internamente, elíptico-arredondados, pubérulos, tricomas alvos, diminutos; margem diminuto-ondulada, rodeada por apêndices filiformes, regulares, retos, espessos, 0,5-1 cm compr.; brácteas sésseis; pedúnculos 3-4 cm compr., pubérulos, inserção cêntrica no receptáculo. Flores estaminadas: tépalas 2, pubérulas; estames 2. Flores pistiladas: não observadas. Drupas não observadas.
Dorstenia acangatara se assemelha a $D$. albertorum Carauta, C.Valente \& Sucre, entretanto, esta última não ocorre na região da Serra da Mantiqueira, além disso $D$. acangatara se difere pelos apêndices filiformes de 1-1,5 cm compr. e ausência de brácteas espatuladas nos ápices dos apêndices. Na Serra da Mantiqueira foi encontrada no estado de MG, com flores no mês III.

Material examinado: MINAS GERAIS: Caratinga, Estação Biológica de Caratinga, Fazenda Montes Claros, 24.III.2000, fl., J.A. Lombardi 3639 (BHCB Holótipo).

\section{Dorstenia arifolia Lam., Encycl. 2: 317. 1786.}

Fig. 1c-f

Caméfitos, 25-50(-80) cm alt.; caule aéreo ereto ou decumbente, hirsuto a tomentoso, tricomas alvos a castanhos, entrenós $1-2 \mathrm{~mm}$ compr. Estípulas $4-10 \mathrm{~mm}$ compr., foliáceas, ovado-deltoides, coriáceas, persistentes, pubérulas a tomentosas, tricomas alvos a castanhos. Folhas inteiras e/ou frequentemente lobado-pinadas, espiraladas a rosuladas; lâminas $12-20 \times 8-12$ $\mathrm{cm}$, cordado-sagitadas, membranáceas, ápice agudo a acuminado, base cordada a sagitada, margem inteira a dentado-crenada, face adaxial glabra a esparsamente escabra, face abaxial 


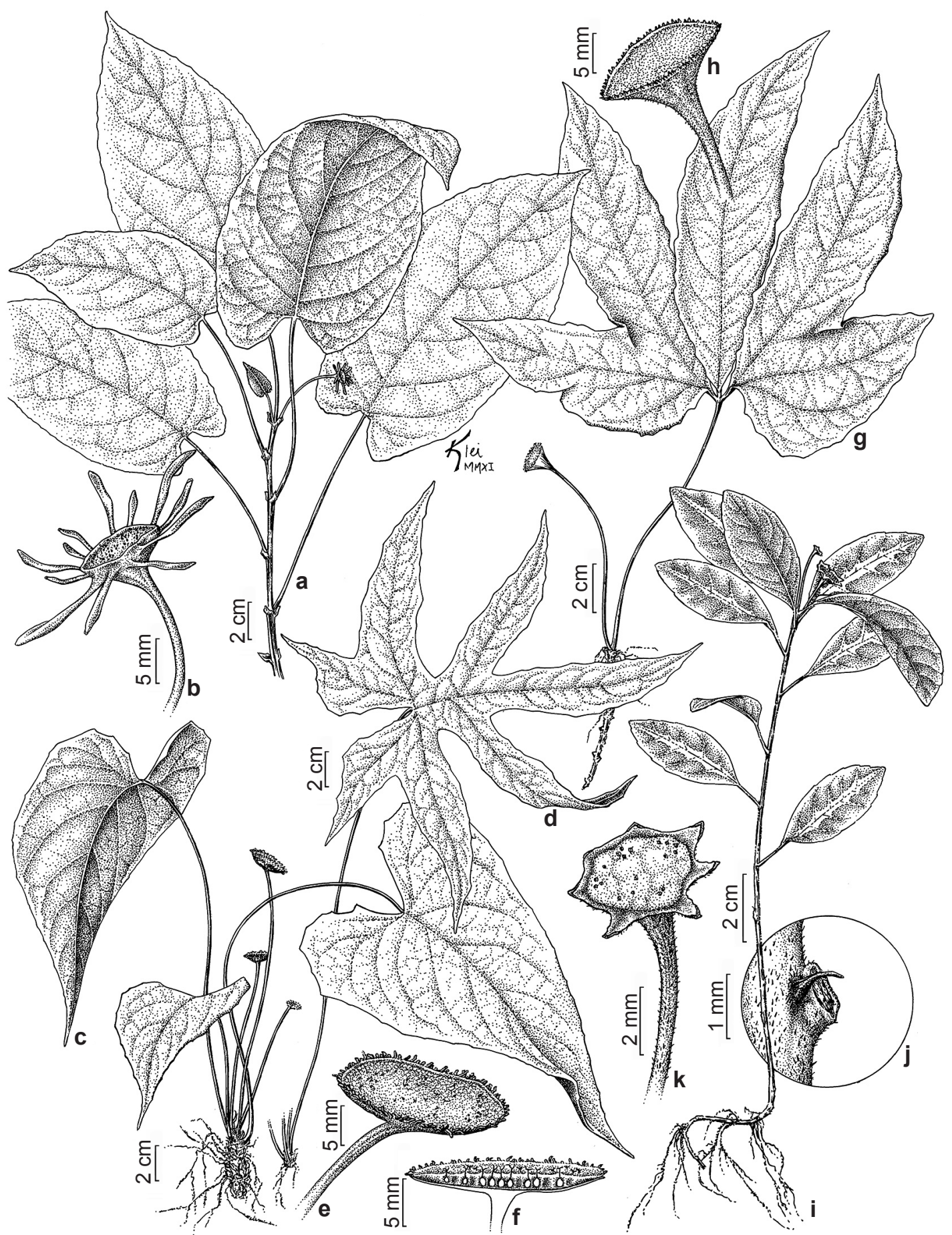

Figura 1-Dorstenia acangatara -a. hábito; b. cenanto com detalhe da margem com apêndices filiformes (J.A. Lombardi 3639). D. arifolia - c. hábito; d. lâmina foliar lobado-pinada; e. cenanto; f. cenanto em corte longitudinal, detalhe das flores pistiladas com ovário e estilete imersos no receptáculo (A. Santos et al. 116). D. Bonijesu - g. hábito; h. inflorescência infundibuliforme (A. Santos et al. 107a) . D. bowmaniana - i. hábito; j. estípula subulada; k. cenanto angulado (J.M.A. Braga et al. 1568).

Figure 1 - Dorstenia acangatara - a. habit; b. coenanthium with detail of the margin with filiform appendages (J.A. Lombardi 3639). D. arifolia c. habit; d. leaf lamina lobed-pinnate; e. coenanthium; f. coenanthium in longitudinal sectioning, detail of the pistilate flowers with ovary and style immersed in the receptacle (A. Santos et al. 116). D. Bonijesu - g. habit; h. inflorescene infundibuliform (A. Santos et al. 107a). D. bowmaniana-i. habit; j. stipule subulate; k. coenanthium angled (J.M.A. Braga et al. 1568). 
escabra a hirsuta; lobos 3-6; nervação actinódroma ou broquidódroma, 8-12 pares de nervuras secundárias, nervuras terciárias reticuladas, bifurcadas; pecíolos 17-30(-43) cm compr., glabros a pubérulos, tricomas alvos a castanhos. Cenantos inteiros, (0,5-)1,5-2,5 cm diâm., pateliformes, externamente arroxeados e internamente vináceos, arredondados quando jovens e elípticos ou oblongo-arredondados posteriormente, pubérulos, tricomas alvos, margem inteira a levemente lobada, bracteada; brácteas sésseis, oblongas, cartáceas; pedúnculos (-5)10-29(-33) cm compr., inserção excêntrica no receptáculo ou algumas vezes com inserção cêntrica. Flores estaminadas: tépalas 2, pubérulas; estames 2. Flores pistiladas: perianto curto lobado; estigma 0,7-0,9 mm compr. Drupas 0,5 mm diâm. Sementes globosas, testa verrucosa.

A espécie apresenta grande variação morfológica nas folhas, que podem ou não ser inteiras ou profundamente lobadas no mesmo indivíduo. A forma do cenanto pode ser arredondada, principalmente quando jovem, a elíptico a oblongo-arredondada, quando adultas. $\mathrm{Na}$ Serra da Mantiqueira foi encontrada no ES, MG e SP, com flores nos meses de I, II, III, V, VI, VIII, X, IX e X, e com frutos em I,II, IV, V, VI e XII. Material selecionado: MINAS GERAIS: Abre Campo, Granada, Área da Usina Hidrelétrica de Granada, 10.IV.1999, fl. e fr., A. Salino \& P.O. Morais 4592 (BHCB, CESJ). Além do Paraíba, 22.II.2008, fl., T. S. Coser 153 (VIC). Canaã, Cachoeira Grande, 13.III.1988, fl., M.F. Vieira 600 (GUA, VIC). Carangola, Fazenda Santa Rita, XII.1987, fl., L.S. Leoni 1 (GUA), Fazenda Santa Rita, sopé do Morro da Torre, fl., 24.IX.2011, A. Santos et al. 138 (SP). Coronel Pacheco, Fazenda da Liberdade, 9.II.1942, fl., E.P. Heringer 920 (SP, VIC). Faria Lemos, Fazenda Santa Rita, I.2002, fl., L.S. Leoni 4844 (GFJP). Jequeri, Área de inundação da Usina de Providência, 19.XI.1997, fl., A. Salino 3745 (BHCB). Juiz de Fora, Fazenda Cachoeirinha, 24.VIII.1969, fl., L. Krieger (CESJ 7123). Muriaé, Fazenda Barra Alegre, 23.X.1989, fl., $R$. Simão-Bianchini 204 (SPF). Nepomuceno, Serra dos Núcleos, 13.II.2003, fl. e fr., A. Valente et al. 261 (CESJ). Raul Soares, Vila Belchior, 24.XI.1992, fl., A.F. Carvalho 257 (SP, VIC). Rio Doce, Santana do Deserto, Fazenda Paraíso, Córrego do Souza, 16.X.1997, fl., I. Cordeiro, 1655 (SP). São Miguel do Anta, Santa Rosa, proximidades do Sítio do Sr. Geraldo, 15.XII.2010, fl. e fr., A. Santos et al. 114, 115 e 116 (SP). Tombos, Pedra Dourada, Sítio do Amadeu Carara, 05.VI.1941, fl., J.E. Oliveira 541 (BHCB, SP). RIO DE JANEIRO: Natividade, 27.XI.2004, fl., L.Y.S. Aona et al. 908 (RB). Porciúncula, Morro da Angola, Fazenda da Angola, 10.I.1984, fl., J. P. P. Carauta 4557 (GUA). SÃO PAULO: Piquete, Benfica, mata do Benfica, 21.III.2007, fl., R.B. Torres et al. 1847 (IAC).
3. Dorstenia bonijesu Carauta \& C.Valente, Atas Soc. Bot. Brasil 1(20): 112. $1983 . \quad$ Fig. 1g-h Criptófitos a hemicriptófitos, $10-50 \mathrm{~cm}$ alt.; caule aéreo ereto, glabro a hirsuto, entrenós 1-3(-5) mm compr. Estípulas 4-6 mm compr., foliáceas ovado-deltoides, cartáceas a coriáceas, persistentes, glabras a hirsutas, tricomas alvos diminutos. Folhas espiraladas; lâminas pseudodígito-trifoliadas, 14 18 × 12-17 larg., ovado-elípticas; membranáceas; margem inteira a crenado-dentada; face adaxial esparsamente hirsuta a escabra, face adaxial hirsuta a levemente escabra, tricomas alvos concentrado nas nervuras; lobos 3, laterais algumas vezes palmatipartidos, ápice agudo, base agudo-arredondada; nervação actinódroma, 6-12 pares de nervuras secundarias no lobo central, nervuras terciárias reticuladas a escaliformes; pecíolos (3-)7-14 cm compr., pubérulos a hirsutos; pseudopecíolos 3, 1-3 mm compr., algumas vezes ausentes. Cenantos inteiros, $1-2 \mathrm{~cm}$ diâm., infundibuliformes, esverdeados, arredondados, pubérulos a tomentosos, tricomas alvos, margem provida de brácteas sésseis, oblongo-deltoides; brácteas pubérulas; pedúnculos $6-17(-24) \mathrm{cm}$ compr., pubérulos, inserção cêntrica no receptáculo. Flores estaminadas: tépalas 2 lobadas, pubérulas; estames 2. Flores pistiladas: perianto curto lobado; estigma alvo, 5-8 mm. Drupas globosas. Sementes globosas, testa verrucosa, esbranquiçada.

$\mathrm{O}$ cenanto infundibuliforme e a morfologia das folhas são únicos no gênero. Quando em estado vegetativo se assemelha a $D$. vitifolia, entretanto, se difere desta por apresentar lâminas foliares pseudodígito-trifoliadas. Endêmica do Brasil, ocorre nos estados do RJ, ES e MG. Na Serra da Mantiqueira foi encontrada no Estado de MG, somente no município de Viçosa. Foi coletada com flores nos meses de I, II, III, XI e XII, e com frutos em I, II e XI.

Material selecionado: MINAS GERAIS: Viçosa, mata do Paraíso, 15.II.2001, fl. e fr., G.E. Valente 633 (R, SP, VIC), trilha dos Gigantes, 25.I.2006, fl. e fr., L. $M$. Araújo (VIC 30133), 25.I.2006, fl., L.M. Araújo (VIC 30134), fl., L.M. Araújo (VIC 30135), 14.III.2008, fl., P.P. Souza 244 (VIC), 13.XII.2010, fl., A. Santos et al. $107 a, 107$ b e 108 (SP).

4. Dorstenia bowmaniana Baker, Refug. Bot. 5: t. 303. 1871.

Fig. 1i-k

Caméfitos, $15-30 \mathrm{~cm}$ alt; caule aéreo ereto, inteiramente fibroso, hirsuto; entrenós longos $0,80-1,5 \mathrm{~cm}$ compr. Estípulas $0,8-1$ $\mathrm{mm}$ compr., subuladas; persistentes a caducas, 
pubérulas, tricomas alvo-acastanhados. Folhas inteiras, espiraladas a dísticas; lâminas $5-7 \mathrm{~cm}$ compr., 2-3,5 cm larg., elípticas a oblongas, membranáceas, ápice agudo, base agudo-atenuada, margem inteira a remotamente denticulada, face adaxial glabra, face abaxial híspida a escabra; nervação broquidódroma, 6-8 pares de nervuras secundárias, usualmente mancha verde-claro ao longo da nervura mediana e também a porção basal das nervuras secundárias, nervuras terciárias reticuladas, inconspícuas; pecíolos $0,5-1,5(-2) \mathrm{cm}$ compr., híspidos a tomentosos. Cenantos inteiros, 0,5-1 cm diâm., pateliformes, esverdeados, angulados, pubérulos, margem provida de brácteas sésseis, ovado-deltoides, geralmente nos ângulos, franja eventualmente vinácea; pedúnculos $0,5-1 \mathrm{~cm}$ compr., pubérulos a tomentosos, inserção cêntrica no receptáculo. Flores estaminadas: distribuídas por todo o cenanto; tépalas 2, pubérulas; estames 2. Flores pistiladas: perianto curto lobado; estigma 2-4 mm compr. Drupas 1-1,5 mm diâm. Sementes ovadas, testa verrucosa, creme-amarrozadas.

Assemelha-se a $D$. turnerifolia pela forma e tamanho das folhas, entretanto, D. bowmaniana se difere por apresentar o cenanto com margem arredondado-angulada, além disso, D. turnerifolia se apresenta como nanofanerófita com caule aéreo de base lenhosa. Na Serra da Mantiqueira foi encontrada no RJ e SP, com flores nos meses de I, XI e X e com frutos em I e XI.

Material selecionado: RIO DE JANEIRO: Itatiaia, Parque Nacional da Tijuca, Maromba, Cachoeira Véu de Noiva, 21.XI.1994, fl., J.M.A. Braga 1568 (GUA). Resende, Vila do Itatiaia, 22-28.XI.1938, fl. e fr., Markgraf \& A.C. Brade 3626 (GUA). São Paulo: Pindamonhangaba, entre a propriedade da Fazenda São Sebastião do Ribeirão Grande e a Pousada Nova Gokula, 27.XII.2011, fl., A. Santos et al. 147 (SP). SÃO PAULO, Serra da Cantareira, 11.I.1914, fl. e fr., F. Tamandaré \& A.C. Brade 6943 (SP).

5. Dorstenia brasiliensis Lam., Encycl. 2: 317. 1786.

Fig. 2a-b

Criptófitos a hemicriptófitos, 5-10 cm

alt.; caule aéreo curto ou ausente, entrenós 1-2 mm compr. Estípulas 4-5 mm compr., foliáceas, ovado-deitoides, cartáceas a coriáceas, persistentes, pubérulas, tricomas concentrados na nervura dorsal; nervura dorsal proeminente; tricomas alvos a amarronzados. Folhas inteiras, espiralas a rosuladas; lâminas 3-7 cm compr., 1,5-4 cm larg., elíptica-oblongas a obovadas, cartáceas a coriáceas, ápice arredondado, emarginado ou obtuso, base arredondada ou auriculado-cordiforme, margem inteira a levemente crenada, face adaxial hirsuta, alvo-amarelados, face abaxial pubescente; nervação craspedódroma, 5-8 pares de nervuras secundárias, nervuras terciárias bifurcadas; pecíolos $1-4 \mathrm{~cm}$ compr., pubescentes, tricomas alvo a castanhos. Cenantos inteiros, planos, (0,5-)1-2 cm diâm., pateliformes, vináceos, arredondados; margem não urceolada, provida de brácteas ovado-deltoides, levemente vináceas; pedúnculos $2,5-4,5 \mathrm{~cm}$ compr., com inserção cêntrica no receptáculo. Flores estaminadas: tépalas 2 lobadas, pubérulas. Flores pistiladas: perianto curto lobado, pubérulo. Drupas 1-1,5 mm diâm. Sementes globosas, testa verrucosas, creme-amarronzadas.

$D$. brasiliensis apresenta-se com folhas arredondadas a cordiformes e D. tubicina Ruiz \& Pav. apresenta-se com folhas cordado-oblongas a elíptico-lanceoladas. Carauta (1978) observa que a semelhança é grande, mas considera as diferenças das características foliares e de ocorrência importantes para a separação das espécies. Entretanto, Berg (2001) considerou D. brasiliensis como uma espécie polimórfica, e as variações nas características foliares observadas seriam decorrentes principalmente da variação ambiental. Para as espécies da região da Serra da Mantiqueira consideramos as variações morfológicas das folhas como plasticidade fenotípica da espécie. No Brasil ocorre em quase todas as regiões, exceção para a região Sul. Para a região da Serra da Mantiqueira o material examinado é escasso e a espécie só foi encontrada em MG, com flores nos meses de I, II, III, VI, X, XI e com frutos em III e XI.

Material selecionado: MINAS GERAIS: Baependi, Toca dos Urubus, 1.XI.2003, fl., F.M. Ferreira et al. 480 (CESJ). Carandaí, 18.II.1946, fl., A.P. Duarte 523 (RB). Poços de Caldas, 27.III.1920, fl. e fr., F.C. Hoehne 3837 (SP). São João Del Rei, Rio das Mortes, Goiabeiras, 22.VI.2006, fl., G. Del-Vechio 67 (R), Tiradentes, Serra de Tiradentes, 12.I.1999, fl., C. Zani (BHCB 49234). SÃO PAULO: Caieiras, 10.X.1945, fl., W. Hoehne (GUA 32255).

6. Dorstenia cayapia Vell., Fl. Flumin. 51. 1825 (1829).

Fig. 2c-d

Criptófitos a hemicriptófitos, $10-15 \mathrm{~cm}$ compr.; caule aéreo curto ou ausente, entrenós 1-2 mm. Estípulas 4-6 mm compr., foliáceas, ovado-deltoides, persistentes, cartáceas a coriáceas pubérulas, tricomas alvos. Folhas inteiras, espiraladas a rosuladas; lâminas 7-10 × 5-7,5 $\mathrm{cm}$, ovadas a cordiformes, membranáceas, ápice arredondado, obtuso, base cordada, margem inteira a remotamente ondulada, face adaxial 


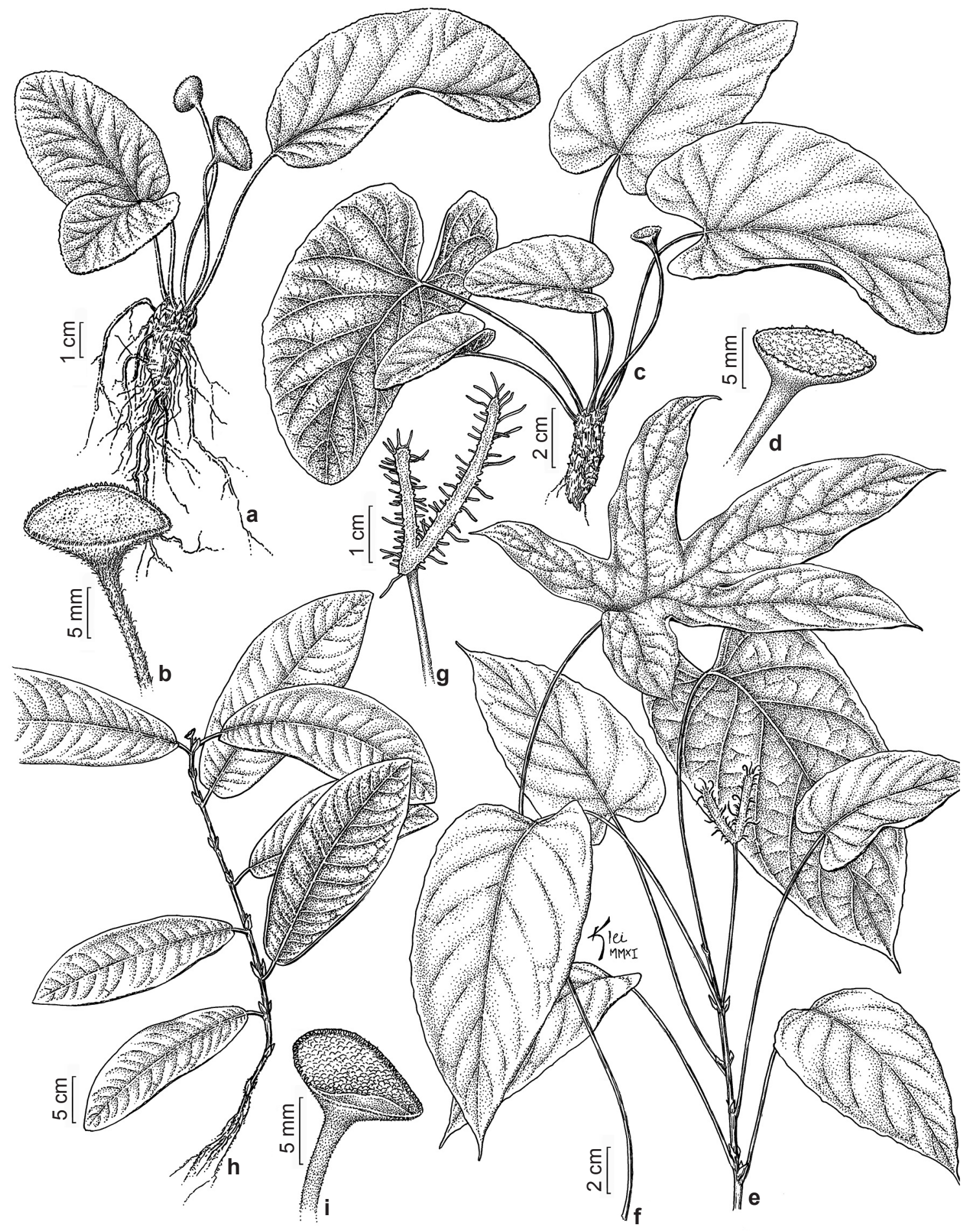

Figura 2 - Dorstenia brasiliensis - a. hábito; b. cenanto (F.C. Hoehne s.n. SP 3837). D. cayapia Vell. - c. hábito; d. cenanto (L. Krieger s.n. GUA 40047). D. dolichocaula - e. hábito (A. Santos et al. 124); f. Lâmina foliar pinado-lobada (A. Santos et al. 123); g. cenanto bifurcado com apêndices (A. Santos et al. 123). D. elata-h. hábito; i. inflorescência (A. Santos et al. 135). Figure 2 -Dorstenia brasiliensis - a. habit; b. coenanthium (F.C. Hoehne s.n. SP 3837). D. cayapia Vell. - c. habit; d. coenanthium (L. Krieger s.n. GUA 40047). D. dolichocaula - e. habit (A. Santos et al. 124); f. leaf lamina lobed-pinnate (A. Santos et al. 123); g. coenanthium bifurcated with appendages (A. Santos et al. 123). D. elata - h. habit; i. inflorescence (A. Santos et al. 135). 
glabra a esparsamente hirsuta, escabra, usualmente variegada, face abaxial hirsuta, tricomas geralmente alvos; nervação craspedódroma, 5-7 pares de nervuras secundárias, nervuras terciárias bifurcadas; pecíolos 6-15 cm compr., hirsutos a pubescentes. Cenantos inteiros, 5-15 mm diâm., pateliformes, planos, vináceo-avermelhados internamente, arredondados, pubérulos; margem provida de brácteas foliáceas curtas, violáceas; pedúnculos 6-10 cm compr., com inserção cêntrica a levemente excêntrica no receptáculo. Flores estaminadas: tépalas 2, pubérula; estames 2. Flores pistiladas: perianto curto lobado. Drupas não observadas.

Berg (2001) reorganizou o grupo e considerou as espécies D. asaroides Gardner, D. paraguariensis (Hassl.) Carauta e D. vitifolia, como subespécies de D. cayapia. Para a região da Serra da Mantiqueira foram encontradas $D$. cayapia e $D$. vitifolia e as diferenças observadas na morfologia das folhas e cenanto são suficientes para separá-las em espécies independentes. D. vitifolia apresenta cenanto com margem espessa e urceolada e as lâminas foliares são lobadas quando adultas diferentemente de $D$. cayapia que apresenta cenanto não urceolado e as lâminas foliares apresentam margem inteira a remotamente ondulada e usualmente variegada. $\mathrm{Na}$ região da Serra da Mantiqueira foi encontrada em MG e RJ. Foi coletada com flores nos meses de I, XI e XII e com frutos em XII.

Material selecionado: MINAS GERAIS: Leopoldina, 11.XII.1985, fl., L. Krieger (GUA 40047). Raul Soares, Vila Belchior, 24.XI.1992, fl., A.F. Carvalho 256(VIC). Rio Casca, Usina Hidrelétrica de Jurumirim, margens do Rio Casca, 8.XI.1998, fl., A. Salino 3940 (BHCB). Rio de Janeiro: Porciúncula, Morro da Angola, Fazenda da Angola, 10.I.1984, fl., J.P.P. Carauta 4556 (GUA).

7. Dorstenia dolichocaula Pilg., Repert. Spec. Nov. Regni Veg. 41: 222. 1937. Fig. 2e-g

Caméfitos a nanofanerófitos, 0,4-1,3 m alt.; caule aéreo geralmente decumbente, simples ou ramificado, glabro a hirsuto; entrenós longos 1,5-4 cm compr. Estípulas 4-8 mm compr., foliáceas, deltoides, persistentes, cartáceas a coriáceas, hirsutas a eventualmente pubérulas; tricomas alvos a castanhos. Folhas inteiras e/ou frequentemente lobado-pinadas, espiraladas; lâminas 14-30 × (4-)10-18 cm, cordado-oblonga a cordado-sagitada, membranáceas a cartáceas, ápice acuminado a longo acuminado, eventualmente caudado, base cordada a sagitada, face adaxial glabra a pubérula, face abaxial pubérula a hirsuta, tricomas concentrados nas nervuras, margem inteira a dentado-crenada ou longo dentado-serrada; lobos 3-6; nervação actinódroma a broquidódroma, 6-9 pares de nervuras secundárias, nervuras terciárias reticuladas a escaliformes; pecíolos $16-28 \mathrm{~cm}$ compr., glabros a pubérulos, tricomas alvos. Cenantos bifurcados, 2-10 cm compr. cada ramo, 2 ramos, pateliformes, externamente esverdeados e internamente arroxeados, pubérulos, tricomas alvos; margem provida de apêndices filiformes; apêndices (1-)3-10 mm compr., pubérulos, tricomas alvos, brácteas sésseis nos ápices dos apêndices e margem do cenanto; pedúnculos 16-27 cm compr., pubérulos a hirsutos, tricomas alvoacastanhados, inserção excêntrica no receptáculo. Flores estaminadas: tépalas 2, glabras a pubérulas, arroxeadas; estames 2, filete delgado, alvo. Flores pistiladas: perianto curto lobado, arroxeado; estigma alvo a arroxeado. Drupas ovadas. Sementes amareladas, testa verrucosa.

Dorstenia ramosa subsp. dolichocaula $e$ D. ramosa subsp. ramosa foram estabelecidas por Berg (2001). Neste trabalho, as subespécies foram tratadas como espécies válidas, visto que D. dolichocaula se difere de D. ramosa, por apresentar entrenós longos com 1,5-4 cm compr., diferentemente de $D$. ramosa que apresenta entrenós menores que $3 \mathrm{~mm}$ compr. Além da diferença dos entrenós que as delimitam, $D$. dolichocaula foi encontrada em toda Mantiqueira, enquanto que $D$. ramosa é ausente e geralmente se distribui em regiões próximas da costa atlântica. $D$. dolichocaula foi encontrada nos estados de MG, SP e RJ, com flores nos meses de I, II, III, IV, X, XI e XII e com frutos em I, II, XI e XII.

Material selecionado: MINAS GERAIS: Coronel Pacheco, Fazenda da Liberdade, 12.II.1942, fl., E.P. Heringer 934 (SP 46410 Parátipo). Descoberto, Reserva Biológica da Represa do Grama, 23.I.2001, fl. e fr., R.C. Forzza et al. 1751 (CESJ, GUA). Juiz de Fora, Fazenda Cachoeirinha, XI.1948, fl., L. Krieger (GUA 39921). Lima Duarte, Serra Negra, fl., F.R. Salimena et al. 2646 (CESJ). Rio Preto, Funil, margem do Rio Funil na trilha para Sumidouro, Fazenda Lamarão, 26.II.1999, fl., R. Mello-Silva et al. 1656 (SPF). Santa Rita de Jacutinga, II.1972, Braga, P.L.S. 2428 (RB, SP). RIO DE JANEIRO: Itatiaia, 15.X.1918, fl., P.C. Porto 783 (RB), Maromba, 23.II.1948, fl. e fr., M.G. Ferricol et al. (SPF 85305), Parque Nacional do Itatiaia, 13.XII.1964, fl., R. Reitz 6806 (GUA), picada Barbosa Rodrigues, 3.II.1967, fl., J.P.P. Carauta 354 (GUA, RB), Serra de Itatiaia, 5.I.1975, fl., J.P.P. Carauta 1771 (GUA). Resende, Parque Nacional do Itatiaia, Vila Itatiaia, próximo a Lagoa Azul, 1.I.1968, fl., J.P.P. Carauta 532 (GUA), Visconde de Mauá, 25.VII.1971, J.P.P. Carauta 1387 (RB Neótipo), Maromba-Visconde 
de Mauá, 16.II.2011, fl., A. Santos et al. 123, 124 (SP). SÃO PAULO: Cruzeiro, estrada da Fazenda Boa Vista, 5.IV.1995, fl., G.J. Shepherd \& R. Goldenberg 95-34 (SPF, UEC). Queluz, 9K m ao norte de Queluz, beira do Rio das Cruzes, 7.IV.1995, fl., L.S. Kinoshita \& I. Kock 95-44 (UEC).

8. Dorstenia elata Hook., Icon. P1. 3: t. 220. 1840.

Fig. 2h-i

Caméfitos a nanofanerófitos, $0,3-1 \mathrm{~m}$ alt; caule aéreo geralmente ereto, púberulo a hirsuto; entrenós $1-3(-4) \mathrm{cm}$ compr. Estípulas $(0,8-) 1-$ $2,5 \mathrm{~cm}$ compr., foliáceas, oblongo-deltoides, persistentes, glabras a hirsutas, cartáceas; nervura mediana proeminente, nervuras secundárias conspícuas, arroxeadas. Folhas inteiras, dísticas levemente espiraladas; lâminas 20-30 × 5-11 cm, elíptico-obovadas, membranáceas a cartáceas, ápice agudo a obtuso-arredondado, base cordada ou aguda a arredondada, margem inteira a denticulada, face adaxial glabra, face abaxial pubérula a pubescente, algumas vezes escabra; nervação broquidódroma, 10-14(-16) pares de nervuras secundárias, nervuras terciárias reticuladas; pecíolos (1-) 1,5-4 cm compr., densamente tomentosos. Cenantos inteiros, $1-3 \mathrm{~cm}$ diâm., pateliformes, externamente arroxeados e internamente verde-claros, arredondados, elípticos a oblongo-arredondados ou algumas vezes côncavos, densamente pubérulos a tomentosos; tricomas alvos; margem provida de brácteas arroxeadas, sem apêndices; brácteas deltoide-oblongas, sésseis, pubérulas, tricomas diminutos, franja presente ou não; pedúnculos 10-18 cm compr., pubérulos a pubescentes, inserção cêntrica no receptáculo. Flores estaminadas: 2 tépalas, pubérulas; estames 2; filetes delgados, 0,5-0,8 mm compr. Flores pistiladas: perianto curto lobado, pubérulo. Drupas globosas 2-3 mm diâm.

A espécie é muito semelhante à Dorstenia mariae e D. sucrei, entretanto se difere destas por apresentar o cenanto com forma arredondada, elíptica a oblongo-arredondada ou algumas vezes côncava, com inserção cêntrica do pedúnculo no receptáculo. Enquanto que D. mariae e D.sucrei apresentam cenanto alongado com inserção excêntrica do pedúnculo no receptáculo, além disso, o cenanto em $D$. mariae é espiralado. Na Serra da Mantiqueira a espécie foi encontrada apenas no município de Carangola em MG, com flores nos meses de III, VI, IX, X e XII e com frutos em X e XII. Material selecionado: MINAS GERAIS: Carangola, 21.III.1987, fl. e fr., L. Krieger (CESJ 21741), Fazenda Santa Rita, VI.1987, fl., L.S. Leoni 169 (R), 10.X.1998, fl. e fr., J.P.P. Carauta et al. 7097 (GUA), Sopé do Morro da Torre, 24.IX.2011, fl., A. Santos et al. 135 (SP), Serra das Velhas, XII.2008, fl., L.S. Leoni 7284 (GFJP).

9. Dorstenia mariae Carauta, J.M.Albuq. \& R.M.Castro, Albertoa 8: 54. 2002 . Fig. 3a-b Caméfitos a nanofanerófitos, 50-70 cm alt.; caule aéreo ereto, pubérulo a hirsuto; entrenós longos 2-4 cm compr. Estípulas 1,5-2,5 cm compr., foliáceas, oblongo-deltoides, persistentes, glabras a esparsamente hirsutas, tricomas alvos, cartáceas; nervura mediana proeminente, nervuras secundárias conspícuas. Folhas inteiras, levemente espiraladas, lâminas 30-33 cm × 8-10 larg., eliptíco-lanceoladas a obovadas, membranáceas a cartáceas, ápice agudoarredondado, base levemente cordada, margem inteira a eventualmente denticulada, geralmente revoluta, face adaxial glabra, face abaxial pubérula, levemente escabra; nervação broquidródoma, 9-11 pares de nervuras secundárias, nervuras terciárias reticuladas a escaliformes; peciolos 1,5-3 cm compr., hirsutos, tricomas alvos a amarelo-amarronzados. Cenantos inteiros, 7-8 cm compr., lineares, espiralados, externamente arroxeados e internamente cremerosados, pubérulos, tricomas alvos a castanhos; margem inteira a ondulada, provida de brácteas sésseis, ovado-deltoides, pubérulas, sem apêndices, franja 1-3 mm alt.; pedúnculos 16-23 cm compr., hirsutos, inserção excêntrica no receptáculo. Flores estaminadas: tépalas 2 lobadas, pubérulas; estame 2; filetes longos 0,5-1 mm compr., delgados, alvos a amarronzados. Flores pistiladas: perianto curto lobado, pubérulo. Drupas não observadas.

Dorstenia mariae se assemelha a $D$. sucrei pela forma das folhas, estípulas e distância dos entrenós, entretanto, se difere desta última por apresentar o cenanto espiralado com margem inteira a eventualmente denticulada. Na região da Serra da Mantiqueira foi encontrada apenas em MG, com flores nos meses de I, II, IX, X e XI e com frutos em II. Material selecionado: MINAS GERAIS: Caratinga, Estação Biológica de Caratinga, 25.IX.1991, fl., L.V. Costa (BHCB 22389). Descoberto, Reserva Biológica da Represa do Grama, 16.I.2000, fl., F.R.G. Salimena et al. (CESJ 30991), II.2001, fl., L.D. Meireles (CESJ 34463 Parátipo), 01.IX.2001, fl., R.M. Castro et al. 618 (CESJ Parátipo), 31.X.2001, fl., R.M. Castro et al. 639 (CESJ Parátipo), 26.XI.2004, fl., C.M. Sakuragui 1630 (RB).

10. Dorstenia strangii Carauta, Bradea 1(42): 433. 1974.

Fig. 3c-d

Caméfitos até $24 \mathrm{~cm}$ compr.; caule aéreo ereto ou decumbente, glabro a pubérulo; entrenós longos, 1,4-2 cm compr. Estípulas foliáceas, 0,6-1 


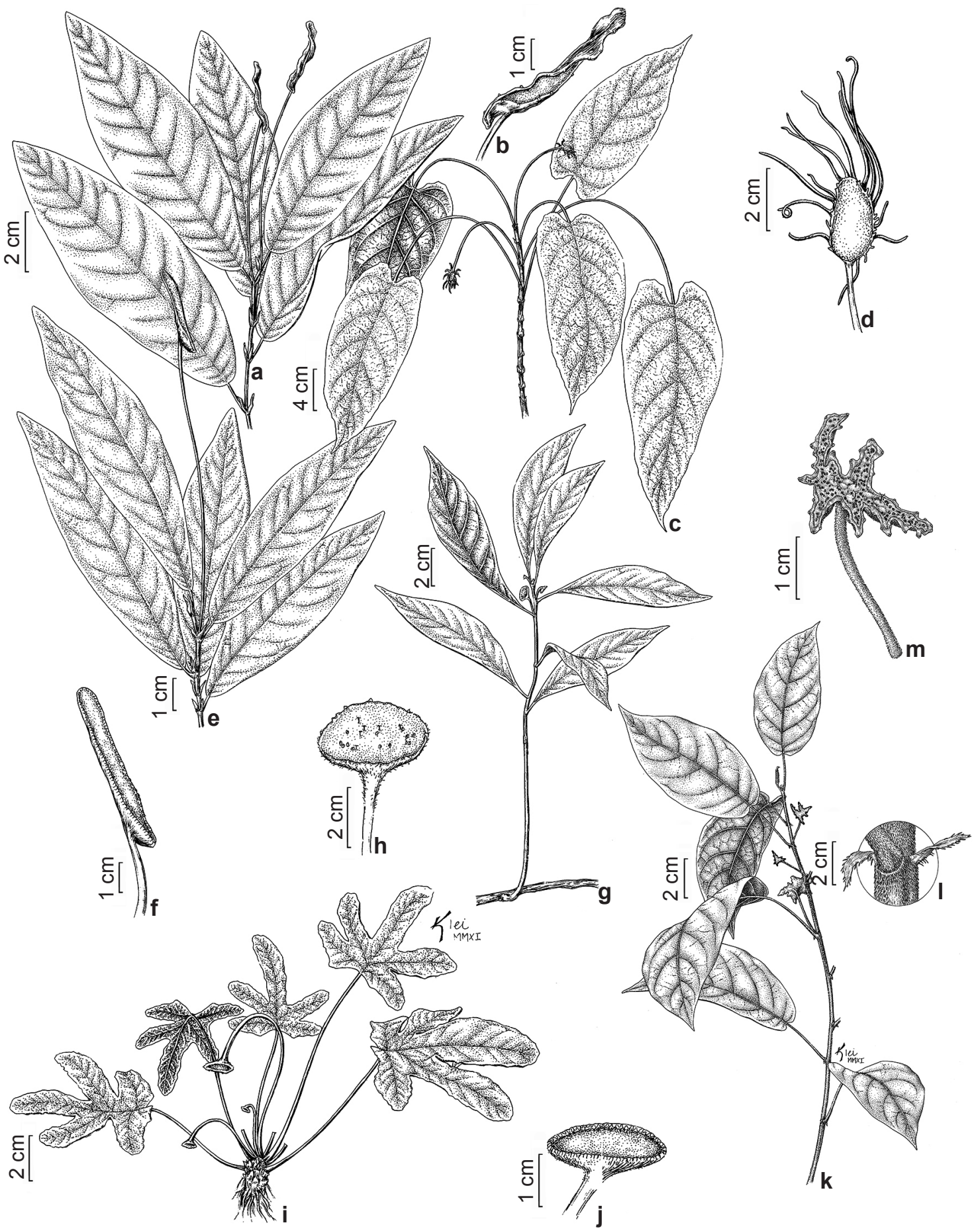

Figura 3 -Dorstenia mariae-a. hábito; b. cenanto espiralado (L.V. Costa s.n. BHCB 22389). D. strangii-c. hábito; d. cenanto com apêndices filiformes irregulares, delgados e curvos (J.R. Saléh s.n. HB 29460). D. sucrei-e. hábito; f. cenanto filiforme (J.A. Lombardi 3676). D. turnerifolia - g. hábito; h. cenanto (J.E. Oliveira 418). D. vitifolia Gardner-i. hábito, detalhe das folhas lobadas; j. cenanto urceolado (A.S. Grotta 4). D. stellaris - k. hábito; 1. estípula; m. cenanto estrelado. (A. Santos et al. 142). Figure 3 - Dorstenia mariae - a. habit; b. coenanthium spiraled (L.V. Costa s.n. BHCB 22389). D. strangii - c. habit; d. coenanthium with appendages filiforms irregular, slender and curved (J.R. Saléh s.n. HB 29460). D. sucrei-e. habit; f. coenanthium filiform (J.A. Lombardi 3676). D. turnerifolia - g. habit; h. coenanthium (J.E. Oliveira 418). D. vitifolia Gardner-i. habit, detail of the leaf lobed; j. coenanthium urceolate (A.S. Grotta 4). D. stellaris - k. habit; 1. stipule; m. coenanthium stellate. (A. Santos et al. 142). 
cm compr., ovadas a oblongas, persistentes, glabras a pubérulas. Folhas inteiras, espiraladas; lâminas 16-22 cm compr., 6-9 cm larg., cordado-sagitadas, membranáceas, ápice agudo a acuminado, base cordada a sagitada, margem inteira a denticulada, face adaxial glabra a esparsamente hirsuta, face abaxial glabra a pubérula; nervação broquidódroma, 6-7 pares de nervuras secundárias, nervuras terciárias reticuladas a escaliformes; pecíolos 20-30 cm compr., glabros a pubérulos. Cenantos inteiros, 1-1,5 cm diam., pateliformes, obovados; margem provida de apêndices filiformes, irregulares, 2-3 cm compr., curvos, delgados, pubérulos; brácteas sésseis; pedúnculos com inserção excêntrica no receptáculo. Flores estaminadas: tépalas 2; estames 2; filete com base dilatada. Sementes verrucosas.

D. strangii se assemelha a D. tentaculata Fisch. \& C.A.Mey. pela presença dos apêndices filiformes na margem do cenanto, entretanto, em D. strangii a forma do cenanto oblongo-obovado e os entrenós longos a diferem de $D$. tentaculata. A espécie foi coletada com flores no mês de III. O último e único registro para a espécie pertence a do seu próprio material tipo em 1974. Poder-se-ia inferir a extinção do táxon in situ, entretanto, seria necessária uma avaliação mais detalhada com buscas exaustivas na localidade típica e arredores. A espécie foi coletada com flores no mês III.

Material examinado: MINAS GERAIS: Bom Jardim de Minas, Serra da Mira, $12 \mathrm{~km}$ do centro de Bom Jardim de Minas, 3.III.1961, fl., J.R. Saléh (HB 29460 Holótipo).

11. Dorstenia sucrei Carauta, Bol. Mus. Bot. Munic. 17: 2. 1974.

Fig. 3e-f

Caméfitos a nanofanerófitos, $30-70 \mathrm{~cm}$

alt.; caule aéreo ereto, hirsuto; entrenós 1,5$2,5 \mathrm{~cm}$ compr. Estípulas 0,5-1,5 cm compr., foliáceas, oblongo-deltoides, persistentes, glabras a pubérulas, cartáceas; nervura mediana proeminente, nervuras secundárias conspícuas. Folhas inteiras, dísticas a espiraladas; lâminas $20-25(-27) \mathrm{cm}$ compr., 5-8,5 cm larg., elípticas, membranáceas a cartáceas, ápice obtuso a acuminado, base aguda, arredondada a cordada, margem inteira a denticulada, face adaxial glabra, face abaxial glabra a hirsuta, escabra, tricomas concentrados nas nervuras, alvos; nervação broquidódroma, 10-12 pares de nervuras secundárias, nervuras terciárias reticuladas; pecíolos 1-3,5 cm compr., hirsutos. Cenantos inteiros, arroxeados externamente, internamente creme-esverdeados, 4-7 cm compr., lineares, filiformes, pubérulos; margem inteira a levemente ondulada, provida de brácteas sésseis ovado-deltoides a oblongo-deltoides, ciliadas, sem apêndices, franja até $2 \mathrm{~mm}$ alt.; pedúnculos 10-17 cm compr., pubérulos, inserção excêntrica no receptáculo. Flores estaminadas: 2 tépalas, pubérulas; estames 2; filetes delgados. Flores pistiladas não observadas.

A espécie se assemelha a $D$. elata e a $D$. mariae pelo porte, forma das folhas e estípulas. Essas variações foram observadas por Berg (2001) que não considerou suficientes para separar D. elata de D. sucrei, sinonimizado-as. D. sucrei se difere de D. elata pela forma do receptáculo e pela inserção do pedúnculo, em D. elata o cenanto é arredondado, elíptico a oblongo-arredondado ou algumas vezes côncavo com inserção cêntrica do pedúnculo no receptáculo e em $D$. sucrei o cenanto é filiforme com inserção excêntrica no receptáculo, enquanto que, D. mariae se difere pelo cenanto espiralado, sendo assim, considerada como válida neste trabalho. Na Serra da Mantiqueira foi encontrada apenas em MG, com flores nos meses de III e XII. Material examinado: MINAS GERAIS: Caratinga, Estação Biológica de Caratinga, 11.XII.1995, fl., $A$. Salino 2370 (BHCB), Fazenda Montes Claros, fl., J.A. Lombardi 3676 (BHCB).

12. Dorstenia turnerifolia Fisch. \& C.A.Mey. Index Seminum (St. Petersburg) 11: 63. 1846.

Fig. 3g-h

Nanofanerófitos, até $40 \mathrm{~cm}$ alt.; caule aéreo ereto, menos frequentemente decumbente, ramificado, parcialmente lignificado na porção basal, glabro a hirsuto; entrenós longos (1-)2-3 cm compr. Estípulas 0,5-1 mm compr., subuladas, estreito-triangulares, persistentes a caducas. Folhas inteiras, dísticas a espiraladas; lâminas 6-11 × 2-3 cm larg., elípticas a oblongo-eípticas, membranáceas, ápice longo acuminado, base aguda a agudo-atenuada, margem inteira a denticulata, face adaxial hirsuta a levemente escabra, tricomas esparsos, alvos, face abaxial hirsuta; nervação broquidódroma, 8-10 pares de nervuras secundárias, nervuras terciárias inconspícuas; pecíolos 0,8-1,5 cm compr., hirsutos a tomentosos. Cenantos inteiros, 0,5-1 cm diâm., pateliformes, arroxeados externamente, verde-claros internamente, arredondados; margem provida de brácteas, brácteas sésseis, ovadodeltoides, hirsutas, tricomas com 0,5-1 mm compr., alvos; pedúnculos $0,5-1 \mathrm{~cm}$ compr., hirsutos a tomentosos, com inserção cêntrica no receptáculo. Flores estaminadas: concentradas na periferia do cenanto; tépalas $2(-3)$, estames $2(-3)$, hirsutas. 
Flores pistiladas: 3 tépalas, hirsutas. Drupas globosas. Sementes globosas, testa verrucosa.

A espécie se assemelha a $D$. bowmaniana pela forma das folhas, entretanto se difere pela forma do cenanto que é arredondado e por apresentar caule aéreo com base lenhosa, enquanto que $D$. bowmaniana, apresenta o cenanto angulado e base do caule aéreo fibrosa. Além disso, D. turnerifolia se apresenta como nanofanerófito podendo atingir até $40 \mathrm{~cm}$ de altura, diferentemente de $D$. bowmaniana que se apresenta como caméfita e atinge até $20 \mathrm{~cm}$ alt. Na Serra da Mantiqueira a espécie foi encontrada em MG, com flores nos meses de III e V e com frutos em III.

Material examinado: MINAS GERAIS: Carangola, 6.III.1907, fl., J.S. Novaes (SP 19606). Caratinga, Estação Biológica de Caratinga, Fazenda Montes Claros, fl., 25.III.2000, J.A. Lombardi 3677 (BHCB 51187, CESJ). Tombos, Usina, 2.V.1941, fl., J.E. Oliveira 418 (SPF).

13. Dorstenia vitifolia Gardner in Fielding \& Gardner, Sert. Pl. 1: t.14. $1843 . \quad$ Fig. 3i-j

Criptófitos a hemicriptófitos atingindo $20 \mathrm{~cm}$ alt.; caule aéreo ereto, geralmente ausente, ereto, pubérulo, tricomas alvos a castanhos; entrenós 1-2 mm compr. Estípulas 4-5 mm compr., foliáceas, ovado-deltoides, coriáceas, persistentes. Folhas inteiras quando jovens lobadas quando adultas, espiraladas a rosuladas; lâminas 6-9,5 × 7-10 $\mathrm{cm}$, ovado-elípticas, lobos 3-5, cartáceas, ápice obtuso a arredondado, base subcordada a truncada, margem inteira a denticulada, face adaxial glabra a esparsamente hirsuta, face abaxial glabra a pubérula, tricomas alvo-amarrozados, concentrado nas nervuras; nervação actinódroma, nervura mediana impressa a plana na face adaxial, proeminente na face adaxial, 4-5 pares de nervuras secundárias no lobo central, nervuras terciárias reticuladas; peciolos 6-15 cm compr., pubérulos, tricomas alvoamarrozados. Cenantos inteiros, 1-1,5 cm diâm., pateliformes, arroxeados externamente e vináceos internamente, arredondados, urceolados, pubérulos; margem provida de brácteas sésseis, ovado-deltoides, pubérulas; pedúnculos 5-15 cm compr., pubérulos, tricomas alvo-amarronzados, inserção cêntrica no receptáculo. Flores pistiladas: perianto curto lobado, pubérulo; estigma castanho. Drupas 2-3 mm diâm. Semente acastanhada, testa lisa.

A espécie se assemelha a $D$. cayapia, pelo porte, aparência do cenanto e pela forma da folha, entretanto, em $D$. vitifolia as folhas jovens nascem arredondadas e inteiras, mas quando adultas apresentam lobos marginais que lembram a folha da videira (Vitis vinifera L.). Além disso, o cenanto é levemente urceolado o que difere de D. cayapia, que apresenta folhas sempre inteiras e cenanto não urceolado. Na Serra da Mantiqueira foi encontrado um único indivíduo no município de Roseira, em SP.

Material examinado: SÃO PAULO: Roseira, RoseiraIbitinga, 14.I.1941, fl., A.S. Grotta 4 (SPF).

Material adicional examinado: SÃO PAULO: São Paulo, Parque Estadual das Fontes do Ipiranga, 25.IV.1991, fl. e fr., S. Romaniuc Neto (SP 248639).

14. Dorstenia stellaris Al. Santos \& Romaniuc, Phytokeys 12: 47-51.2012. Fig. 3k-m Caméfitos $30-70 \mathrm{~cm}$ alt.; caule aéreo inteiramente fibroso, hirsuto; entrenós $1-2,5 \mathrm{~cm}$ compr. Estípulas 1-2 mm compr., subuladas, estreito-triangulares, ciliadas, persistentes a caducas, tricomas alvos. Folhas inteiras dísticas a espiraladas; lâminas 8-12 × 3,5-5 $\mathrm{cm}$, membranáceas, ápice longo acuminado, base cordada, face adaxial escabra, tricomas esparsos, alvos, face abaxial pubérula, tricomas concentrados nas nervuras, desprovida de manchas; margem inteira a denticulada; pecíolos 2,5-5 cm compr., híspidos a tomentosos; nervação broquidódroma; 5-6 pares de nervuras secundárias; nervuras terciárias escaliformes. Cenantos inteiros, 1-2 cm diâm., pateliformes, estrelados, 3-5 angulados, pubérulos; margem provida de brácteas sésseis, $0,5-1 \mathrm{~mm}$ compr., frequentemente nos ápices dos ângulos, pubérulas, franja $0,5-0,7 \mathrm{~mm}$ alt., esverdeada a vinácea; pedúnculos 1,5-2,5 cm compr., pubérulos. Flores estaminadas: distribuídas por todo o cenanto; estames 2. Flores pistiladas: perianto curto lobado, pubérulo; estigma 0,5-1 $\mathrm{mm}$ compr, delgado, alvo. Drupas elípticas; estigma persistente. Sementes testa lisa.

A forma do cenanto aproximam a espécie de $D$. bowmaniana e $D$. carautae, entretanto, $D$. stellaris se difere destas por apresentar cenanto irregular-estrelado e lâmina foliar com base cordada. Com ocorrência restrita, a espécie só foi encontrada em uma localidade em SP. Foi coletada com flores em III e XI e frutos no mês de III.

Material selecionado: SÃO PAULO: Pindamonhangaba, Ribeirão Grande, Fazenda São Sebastião do Ribeirão Grande, 30.III.1994, fl. e fr., I. Cordeiro et al. 1323 (SP Parátipo). Entre a Fazenda São Sebastião do Ribeirão Grande e a Pousada Nova Gokula, 26.XI.2011, fl., $A$. Santos et al. 142 (SP Holótipo), 143 (SP Parátipo), 144 (SP Parátipo), 145 (SP Parátipo), 146 (SP Parátipo). 


\section{Agradecimentos}

Agradecemos ao Conselho Nacional de Desenvolvimento Científico e Tecnológico CNPq, a bolsa de Mestrado concedida à primeira autora, $\mathrm{e}$ a bolsa de Pós-Doutorado concedida ao Pesquisador de Pós-Doutorado Dr. Marcelo Dias Machado Vianna Filho. Agradecemos também à Coordenação de Aperfeiçoamento de Pessoal de Nível Superior - CAPES, a bolsa de Mestrado concedida a Patricia Aparecida de São José. Os autores também são gratos ao apoio institucional concedido pela Dra. Inês Cordeiro, e ao Programa de Pós-graduação em Biodiversidade Vegetal e Meio Ambiente do Instituto de Botânica de São Paulo.

\section{Referências}

Bell, A.D. 1993. Plant form: an illustrated guide to flowering plant morphology. Oxford University Press, Oxford. 341p.

Berg, C.C. 2001. Moreae, Artocarpeae, and Dorstenia (Moraceae). With introductions to the family and Ficus and with additions and corrections to Flora Neotropica Monograph 7. Flora Neotropica Monograph 83. The New York Botanical Garden, New York. Pp. 346.

Berg, C.C. \& Hijman, M.E.E. 1999. The genus Dorstenia (Moraceae). Ilicifolia 2: 1-211.

BFG. 2015. Growing knowledge: an overview of Seed Plant diversity in Brazil. Rodriguésia 66: 1085-1113.

Carauta, J.P.P. 1978. Dorstenia L. (Moraceae) do Brasil e países limítrofes. Rodriguésia 29: 53233.

CETEC/Fundação Centro Tecnológico de Minas Gerais. 1983. Diagnóstico Ambiental do Estado de Minas Gerais. Vol. 1. CETEC, Belo Horizonte. $158 \mathrm{p}$.

Colabardini, M.F.T. 2003. São João da Boa Vista: a paisagem geográfica da escarpa da Mantiqueira. Tese de Mestrado, Universidade Estadual Paulista, Rio Claro. 130p.

Fidalgo, O. \& Bononi, V.L.R. (coords.). 1989. Técnicas de coleta, preservação e herborização de material botânico. Instituto de Botânica, São Paulo. 62p.

Font Quer, P. 1985. Diccionario de botanica. Editorial Labor S.A., Barcelona. 1244p.

Garcia Junior, G. 2011. Caminhos da Mantiqueira. São Paulo. Empresa das Artes, São Paulo. 204p.

Hickey, L.J. 1973. A revised classification of architecture of dicotyledonous leaves. American Journal of Botany 60: 17-33.

Hueck, K. 1972. As florestas da América do Sul Ecologia, composição e importância econômica. Polígono, São Paulo. 466p.
Lawrence, G.H.M.; Günther Buchheim, A.F.; Daniels, G.S. \& Dolezal, H. (eds.). 1968. BotanicoPeriodicum-Huntianum. Hunt Botanical Library, Pittsburgh. 1063p.

Lima, T.T. 2008. Bromeliaceae da Serra da Mantiqueira: distribuição geográfica e conservação. Dissertação de Mestrado. Instituto de Botânica da Secretaria do Meio Ambiente, São Paulo. 341p.

Mcneill, J. \& Turland, N.J. 2011. Synopsis of proposals on Botanical Nomenclature - Melboune 2011: a review of the proposals concerning the International Code of Botanical Nomenclature submitted to the XVIII International Botanical Congress. Taxon 60: 243-286.

McNeill, J.; Barrie, F.R.; Buck, W.R.; Demoulin, V.; Greuter, W.; Hawksworth, D.L.; Herendeen, P.S.; Knapp, S.; Marhold, K.; Prado, J.; Prud'homme Van Reine, W.F.; Smith, G.F.; Wiersema, J.H. \& Turland, N.J. 2012. International Code of Nomenclature for algae, fungi, and plants (Melbourne Code). Regnum Vegetabile 154: 1-240.

Mendes Júnior, L.O.; Antoniazzi, M.; Viera, M.C.W. \& Sucemihl, P. 1991. Relatório Mantiqueira. FEDAPAM, São Paulo. 49p.

Mori, S.A.; Silva, L.A.M.; Lisboa, G. \& Coradin, L. 1989. Manual de manejo do herbário fanerogâmico. CEPLAC, Ilhéus. 104p.

Prado, J.; Hirai, R.Y. \& Giulietti, A.M. 2011. Mudanças no novo código de nomenclatura para algas, fungos e plantas (Código de Melbourne). Acta Botanica Brasilica 25: 729-731.

Pelissari, G. \& Romaniuc Neto, S. 2013. Ficus (Moraceae) da Serra da Mantiqueira, Brasil. Rodriguésia 64: 91-111.

Radford, A.E.; Dickison, W.C.; Massey, J.R. \& Bell, C.R. 1974. Vascular plant systematics. Harper \& Row Publishers, New York. 891p.

Raunkiaer, C. 1934. The life forms of plants and statistical plant geography. Oxford, Claredon. 1934 p.

Rizzini, C.T. 1979. Tratado de fitogeografia do Brasil: aspectos sociológicos e florísticos. Hucitec, São Paulo.

Santos, A. 2012. Moraceae Gaudich. (excl. Ficus) da Serra da Mantiqueira. Dissertação de Mestrado. Instituto de Botânica da Secretaria de Estado e Meio Ambiente, São Paulo. 192p.

Santos, A. \& Romaniuc Neto, S. 2012. A new species of Dorstenia (Moraceae) from southeastern Brazil. Phytokeys 12: 47-51.

Saout, S.; Hoffmann, M.; Shi, Y.; Hughes, A.; Bernard, C.; Brooks, T.M.; Bertzky, B.; Butchart, S.H.M.; Stuart, S.N.; Badman, T. \& Rodrigues, A.S.L. 2014. Protected areas and effective biodiversity conservation. Science 342: 803-805.

Stearn, W.T. 2004. Botanical latin. $4^{\text {a }}$ ed. Timber Press, Oregon. $456 \mathrm{p}$. 
Thiers, B. 2014. [continuously updated]. Index Herbariorum: A global directory of public herbaria ans associated staff. New York Botanical Garden's Virtual Herbarium, Disponível em <http:// sweetgum.nybg.org/ih/>. Acesso em 26/04/2014.

Várzea, A. 1942. Relevo do Brasil. Revista Brasileira de Geografia 4: 97-130.
Vianna Filho, M.D.M. 2012. Filogenia de Dorstenia sect. Dorstenia L. e Taxonomia do Clado Arifolia. Tese de Doutorado. Universidade Federal do Rio de Janeiro, Rio de Janeiro. 182p.

Weberling, F. 1989. Morphology of flowers and inflorescences. Cambridge University Press, New York. 415p. 